REVIEW ARTICLE

Milk and dairy products: good or bad for human health? An assessment of the totality of scientific evidence

\author{
Tanja Kongerslev Thorning', Anne Raben', Tine Tholstrup', Sabita S. Soedamah-Muthu², \\ lan Givens ${ }^{3}$ and Arne Astrup ${ }^{1 *}$ \\ 'Department of Nutrition, Exercise and Sports, Faculty of Science, University of Copenhagen, Copenhagen, Denmark; \\ ${ }^{2}$ Division of Human Nutrition, Wageningen University, Wageningen, The Netherlands; ${ }^{3}$ Centre for Food, Nutrition and \\ Health, University of Reading, Reading, UK
}

\title{
Abstract
}

Background: There is scepticism about health effects of dairy products in the public, which is reflected in an increasing intake of plant-based drinks, for example, from soy, rice, almond, or oat.

Objective: This review aimed to assess the scientific evidence mainly from meta-analyses of observational studies and randomised controlled trials, on dairy intake and risk of obesity, type 2 diabetes, cardiovascular disease, osteoporosis, cancer, and all-cause mortality.

Results: The most recent evidence suggested that intake of milk and dairy products was associated with reduced risk of childhood obesity. In adults, intake of dairy products was shown to improve body composition and facilitate weight loss during energy restriction. In addition, intake of milk and dairy products was associated with a neutral or reduced risk of type 2 diabetes and a reduced risk of cardiovascular disease, particularly stroke. Furthermore, the evidence suggested a beneficial effect of milk and dairy intake on bone mineral density but no association with risk of bone fracture. Among cancers, milk and dairy intake was inversely associated with colorectal cancer, bladder cancer, gastric cancer, and breast cancer, and not associated with risk of pancreatic cancer, ovarian cancer, or lung cancer, while the evidence for prostate cancer risk was inconsistent. Finally, consumption of milk and dairy products was not associated with all-cause mortality. Calcium-fortified plant-based drinks have been included as an alternative to dairy products in the nutrition recommendations in several countries. However, nutritionally, cow's milk and plant-based drinks are completely different foods, and an evidence-based conclusion on the health value of the plant-based drinks requires more studies in humans.

Conclusion: The totality of available scientific evidence supports that intake of milk and dairy products contribute to meet nutrient recommendations, and may protect against the most prevalent chronic diseases, whereas very few adverse effects have been reported.

Keywords: obesity; type 2 diabetes; cardiovascular disease; osteoporosis; cancer; mortality

Received: 7 June 2016; Revised: 4 October 2016; Accepted: 21 October 2016; Published: 22 November 2016

$\mathrm{S}$ everal media stories and organisations claim that dairy increases risk of chronic diseases including obesity, type 2 diabetes, cardiovascular disease, osteoporosis, and cancer. Therefore, there is an increasing scepticism among the general consumers about the health consequences of eating dairy products. This is reflected in an increasing consumption of plant-based drinks, for example, based on soy, rice, almond, or oats. Dairy is an essential part of the food culture in the Nordic countries; thus, inclusion of milk and dairy products in the diet may be natural for many Nordic individuals. The major causes of loss of disease-free years in the Nordic countries today are type 2 diabetes, cardiovascular diseases, and cancers. Moreover, the increasing prevalence of obesity greatly increases the risk of these chronic diseases. Given the increasing prevalence of these chronic diseases, it is critically important to understand the health effects of milk and dairy products in the diet. Accordingly, this narrative review presents the latest evidence from metaanalyses and systematic reviews of observational studies and randomised controlled trials on dairy intake (butter excluded) and risk of obesity, type 2 diabetes, cardiovascular disease, osteoporosis, and cancer as well as all-cause mortality.

We aim to answer the key questions: 1) For the general consumer, will a diet with milk and dairy products overall provide better or worse health, and increase or decrease risk of major diseases and all-cause mortality than a diet 
with no or low content of milk and dairy products? 2) Is it justified to recommend the general lactose-tolerant population to avoid consumption of milk and dairy products? 3) Is there scientific evidence to substantiate that replacing milk with plant-based drinks will improve health?

\section{Obesity and type 2 diabetes}

A large share of the on-going increase in prevalence of type 2 diabetes is driven by the obesity epidemic $(1,2)$, and it is therefore relevant to assess the role of milk and dairy products for body weight control. Childhood overweight and obesity worldwide is a major contributor to the current obesity epidemic, and childhood obesity frequently tracks into adulthood (3). Therefore, early prevention of childhood obesity is important. A metaanalysis showed that among children in the pre-school and school age, there was no association between dairy intake and adiposity (4). However, there was a modestly protective effect in adolescence. A recent meta-analysis by Lu et al. (5) found that children in the highest dairy intake group were $38 \%$ less likely to be overweight or obese compared to those in the lowest dairy intake group. An increase in dairy intake of one serving per day was associated with a $0.65 \%$ lower body fat and a $13 \%$ lower risk of overweight or obesity.

Milk and dairy products are good sources of highquality protein. Protein is important during weight loss and subsequent weight maintenance due to the high satiating effect which helps to prevent over-consumption of energy and thereby reduces body fat stores $(6,7)$. Furthermore, dairy protein is a good source of essential amino acids for muscle protein synthesis and thus helps to maintain the metabolically active muscle mass during weight loss (8). Meta-analyses support that in adults, dairy products facilitate weight loss and improve body composition, that is, reduce body fat mass and preserve lean body mass during energy restriction and in short-term studies (9-11). The effect of an increased dairy consumption on body weight in long-term studies ( $>1$ year) and in energy balance studies is less convincing $(10,11)$. This is likely due to the opposing effects of dairy on body composition, that is, reduction of fat mass and preservation of lean body mass.

Meta-analyses assessing the role of intake of milk and dairy products on risk of type 2 diabetes have consistently found no or a slight beneficial effect of dairy intake on diabetes risk (12-15). This is consistent with a Mendelian randomisation study using genetic polymorphisms for the lactase gene, which showed that milk intake assessed by lactose tolerance was not associated with risk of type 2 diabetes or obesity (16). The most recent meta-analysis on dairy intake and diabetes incidence included 22 cohort studies with a total of 579,832 subjects and 43,118 type 2 diabetes cases (17). An inverse association between total dairy and yoghurt intake and risk of type 2 diabetes was reported although there was no association with milk intake. The benefits of fermented dairy products (cheese and yoghurt) in relation to type 2 diabetes may be due to their effect on the gut microbiota $(18,19)$. Other studies have identified that whey protein (primarily in milk and yoghurt) can reduce postprandial plasma glucose concentration in type 2 diabetic subjects (20). This effect may be due to the branched chain amino acids in the whey protein fraction, particularly leucine which has been shown to induce a greater stimulation of glucose-dependent insulinotropic polypeptide (GIP), but not glucagon like peptide 1 (GLP-1), compared to other amino acids (21). The GIP response is possibly a key factor in the higher insulin response and the subsequent lowering of blood glucose seen after whey ingestion, at least in healthy subjects. In addition to the insulinotropic effect of milk, a recent study has indicated that dairy may also improve insulin sensitivity (22).

\section{Conclusion on obesity and type 2 diabetes}

A diet high in milk and dairy products reduces the risk of childhood obesity and improves body composition in adults. This likely contributes to lower the risk of developing type 2 diabetes. Additionally, dairy product consumption during energy restriction facilitates weight loss, whereas the effect of dairy intake during energy balance is less clear. Finally, there is increasing evidence suggesting that especially the fermented dairy products, cheese and yoghurt, are associated with a reduced risk of type 2 diabetes.

\section{Cardiovascular disease}

Low-fat, calcium-rich dairy products are generally considered to lower blood pressure. This was supported by a meta-analysis of six observational studies, whereas no association was found with intake of high-fat dairy products (23). High-fat dairy products are known to increase high density lipoprotein (HDL)- and low density lipoprotein (LDL)-cholesterol concentrations. The latter normally predicts risk of cardiovascular disease (24), but this may depend on the size of the LDL-cholesterol particles. Small, dense LDL particles are more atherogenic than their larger counterparts (25-28) due to their lower affinity for the LDL-receptor and higher susceptibility to oxidation (29). In agreement, some of the fatty acids typically found in milk and dairy products have been associated with less small, dense LDL particles (4:0-10:0 and 14:0 in the diet, and 15:0 and 17:0 in serum phospholipids) (30). In addition, the minerals in milk and dairy products have been shown to attenuate the LDL-response to high-fat dairy intake $(31,32)$.

Among high-fat dairy products, cheese in particular does not seem to increase LDL-cholesterol to the extent expected, based on the high content of saturated fat (33). When compared to habitual diet with a lower total and 
saturated fat content (33), or compared to diets with lower total fat content but higher content of high-GI carbohydrates $(34,35)$, a high intake of cheese was found not to increase LDL-cholesterol. A meta-analysis of randomised controlled trials studying the effect of cheese consumption compared with other foods on blood lipids and lipoproteins showed that cheese caused lower total cholesterol, LDL-cholesterol, and HDL-cholesterol concentrations compared with butter (36). Compared with milk, however, there was no statistically significant difference in blood lipids $(32,37)$. Several meta-analyses have been conducted on the relationship between intake of milk and dairy products and risk of developing cardiovascular disease. There was no consistent association between milk or dairy intake and cardiovascular disease, coronary heart disease or stroke in a meta-analysis by Soedamah-Muthu et al. (38). In a recent update, including a higher number of prospective cohort studies, there was a significant inverse association between milk intake and stroke, with a $7 \%$ lower risk of stroke per $200 \mathrm{ml}$ milk/day, but considerable heterogeneity. Further, stratification for Asian and Western countries showed a more marked reduction in risk in Asian than in Western countries. This is consistent with a previous meta-analysis by $\mathrm{Hu}$ et al. (39) showing a non-linear dose-response relationship between milk intake and risk of stroke, with the highest risk reduction of $7-8 \%$ with a milk intake of $200-300 \mathrm{ml} /$ day. Also, the meta-analyses by $\mathrm{Hu}$ et al. (39) and de Goede et al. (40) both showed an inverse association between cheese intake and stroke, however only borderline significant in the latter. Accordingly, another meta-analysis on dairy and cardiovascular disease found that intake of cheese and milk as well as yoghurt was inversely associated with cardiovascular disease risk (41). A later meta-analysis by Qin et al. (42) found that dairy intake was associated with a $12 \%$ lower risk of cardiovascular disease, and 13\% lower risk of stroke as compared to individuals with no or a low dairy consumption (42). Likewise, a recent and comprehensive meta-analysis, including 31 cohort studies, suggested that a high dairy intake was associated with a $9 \%$ lower risk of stroke, whereas no association was found with total cardiovascular disease or coronary heart disease (43). Moreover, a high intake of cheese was associated with an $8 \%$ lower risk of coronary heart disease and a 13\% lower risk of stroke. In addition, high plasma levels of the saturated fatty acid C 17:0, which primarily originates from dairy, were found to be associated with a reduced risk of coronary heart disease (44). Finally, a meta-analysis by O'Sullivan et al. (45) found no indication of total dairy intake or any specific dairy product being associated with an increased cardiovascular mortality. Studies are emerging showing that dairy products, particularly the low-fat types, cluster within a healthy dietary pattern (46), and therefore, the risk of residual confounding in the observational studies cannot be ruled out.

In accordance with the latest meta-analyses presented above, the latest Nordic Nutrition Recommendations have concluded that high consumption of low-fat milk products is associated with reduced risk of hypertension and stroke (47).

\section{Conclusion on cardiovascular disease}

The overall evidence indicates that a high intake of milk and dairy products, that is, $200-300 \mathrm{ml} / \mathrm{day}$, does not increase the risk of cardiovascular disease. Specifically, there is an inverse association with risk of hypertension and stroke.

\section{Bone health and osteoporosis}

Milk and dairy products contain a number of nutrients that are required for building strong bones in childhood and for their maintenance during adulthood with the aim to reduce osteoporosis and bone fractures in older age (48). The European Commission has concluded that protein, calcium, phosphorus, magnesium, manganese, zinc, vita$\min \mathrm{D}$, and vitamin $\mathrm{K}$ are necessary for maintaining normal bones (European Commission regulation 2012). With the exception of vitamin $\mathrm{D}$, these nutrients are all present in significant amounts in milk and dairy products.

Osteoporosis has been described as a 'paediatric disease with geriatric consequences' as low milk, and hence, low mineral intake during childhood and adolescence has been associated with significantly increased risk of osteoporotic fractures in middle and older age, particularly in women $(49,50)$. A recent study indicated that in children and adolescents, except for those with very low calcium intakes, magnesium intake may be more important than calcium in relation to bone development (51). Calcium intake was found not to be significantly associated with total bone mineral content or density, whereas intake of magnesium and the amount absorbed were key predictors of bone mass. The extent to which these results can be extrapolated to the general population is uncertain, but milk and dairy products are important sources of magnesium and hence important supporters of bone growth during adolescence. In a meta-analysis by Huncharek et al. (52), dairy products, with or without vitamin D supplementation, increased total body and lumbar spine bone mineral content in children with low baseline dairy intake, whereas no effect was found for children with a high baseline dairy intake. Thus, there may be a threshold above which increasing intake of dairy products or dairy-calcium does not additionally benefit bone mineral content or density in children.

In adults, interactions between calcium, phosphorus, protein and vitamin $\mathrm{D}$ reduce bone resorption and increase bone formation, thereby attenuating age-related bone loss (53). Possibly due to the complex interaction 
between nutrients and the multifactorial nature of bone fractures, it has been difficult to establish whether or not a low intake of milk and dairy in adulthood increases the risk of osteoporosis and bone fractures. Hence, to date, meta-analyses have not supported a protective effect of milk and dairy intake in adulthood on risk of osteoporosis and bone fractures $(54,55)$. Nevertheless a recent systematic review concluded that calcium and dairy are important contributors to bone health in adults (56).

In the 2015-2020 Dietary Guidelines for Americans, it was stated that 'Healthy eating patterns include fat-free and low-fat (1\%) dairy, including milk, yoghurt, cheese, or fortified soy beverages (commonly known as "soymilk"). Those who are unable or choose not to consume dairy products should consume foods that provide the range of nutrients generally obtained from dairy, including protein, calcium, potassium, magnesium, vitamin D, and vitamin A (e.g. fortified soy beverages)'. Although the focus is on achieving the nutrient requirements by foods rather than supplements, plant-based beverages typically contain inorganic chemical forms of calcium, which may actually increase cardiovascular risk $(56,57)$. As calcium in dairy is organic, milk and dairy products should still be considered the superior sources of calcium (58). Yet, future studies need to address whether or not vitamin $\mathrm{D}$ fortification of dairy products is crucial for these to have a positive effect on bone fracture risk.

\section{Conclusion on bone health and osteoporosis}

The present evidence suggests a positive effect of milk and dairy intake on bone health in childhood and adolescence, but with only limited evidence on bone health in adulthood and on the risk of bone fractures in older age.

\section{Cancer}

In population studies, dairy has been associated positively and negatively with various cancers, but most have been based on limited evidence and very few findings remain robust. Dairy products contain a variety of bioactive compounds that could exert both positive and negative effects on carcinogenesis. The positive effects may be related to the content of calcium, lactoferrin, and fermentation products, whereas the negative effects could be linked to the content of insulin-like growth factor I (IGF-1) (59). The World Cancer Research Fund (WCRF) continuously and systematically reviews the evidence on diet and physical activity in relation to prevention of cancer, and specific areas are updated when new evidence has emerged.

Colorectal cancer is the second most common cause of death among cancers in developed countries. Even though colorectal tumourigenesis is a complex process, epidemiological and experimental data indicate that milk and dairy products have a chemopreventive role in the pathogenesis. In the 2011 WCRF report on colorectal cancer, it was concluded that consumption of milk and calcium probably reduces the risk of this cancer (60). Likewise, in meta-analyses, dairy intake has consistently been associated with a decreased risk of colorectal cancer $(61,62)$ and colon cancer (63). The most recent meta-analysis by Ralston et al. (64) reported $26 \%$ lower colon cancer risk in males consuming $525 \mathrm{~g}$ of milk per day, whereas no association was found in females.

The link between dairy intake and colorectal cancer is considered to be mainly due to the calcium derived from dairy, with a $24 \%$ risk reduction with a dairy-calcium intake of $900 \mathrm{mg} /$ day (65). The proposed mechanisms behind this are calcium binding to secondary bile acids and ionised fatty acids, thereby reducing their proliferative effects in the colorectal epithelium (66). Also, calcium may influence multiple intracellular pathways leading to differentiation in normal cells and apoptosis in transformed cells (67). Accordingly, a number of studies have reported reduced cell proliferation in the colon and rectum with intake of calcium and dairy products (68-72).

In the 2010 WCRF report on breast cancer, it was concluded that the evidence for dairy intake and risk of breast cancer is non-conclusive (73). In accordance with a meta-analysis from 2011 on prospective cohort studies (74), a recent meta-analysis by Zang et al. (75), however, suggested that a high (>600 g/d) and modest (400-600 $\mathrm{g} / \mathrm{d}$ ) dairy intake was associated with a reduced risk of breast cancer $(10 \%$ and $6 \%$, respectively) compared with a low dairy intake $(<400 \mathrm{~g} / \mathrm{d})$. Within dairy subgroups, particularly yoghurt and low-fat dairy were found to be inversely associated with the risk of developing breast cancer. As calcium and vitamin D supplementation was previously shown to reduce risk of breast cancer in the Women's Health Initiative (76), these nutrients could be involved in the underlying mechanisms.

According to the 2014 WCRF report on prostate cancer, dairy may be associated with a limited-suggestive increased risk of prostate cancer, but the current evidence is limited (77). However, this conclusion was substantiated by the most recent meta-analysis by Aune et al. (78), which suggested that a high intake of dairy products, milk, low-fat milk, cheese, and calcium were associated with a $3-9 \%$ increased risk of prostate cancer. The mechanism behind this was suggested to be an increased circulating concentration of IGF-1, which has been previously shown to be associated with an increased prostate cancer risk (79).

The 2015 WCRF report on bladder cancer suggested that the evidence for milk and dairy on bladder cancer risk was inconsistent and inconclusive (80). Two metaanalyses on milk intake and bladder cancer risk have suggested a decreased risk of bladder cancer with a high intake of milk $(61,81)$. Others have found no association between milk and dairy intake and risk of bladder cancer risk (82), but none have suggested an adverse effect. 
Of the cancer types for which the associations with dairy intake were not presented in the WCRF reports, recent meta-analyses have suggested no association between dairy intake and risk of ovarian cancer (83), lung cancer $(84,85)$, or pancreatic cancer (86) and an inverse association between dairy intake and risk of gastric cancer in Europe and the United States (87).

\section{Studies in lactose-intolerant individuals}

In a limited number of subjects, potential differences in cancer risk and mortality between lactose-tolerant and lactose-intolerant individuals (self-reported or assessed by polymorphisms for the lactase gene) have been reported under the assumption that lactose-intolerant individuals consume less milk. However, there may also be other differences between these two groups that need to be taken into consideration, for example, genetics, ethnicity, other dietary habits, smoking, physical activity, and socioeconomic factors.

Bácsi et al. (88) examined the role of genetically determined differences in the ability to degrade lactose and showed that subjects with deficiencies in the genes coding for lactase (i.e. subjects not drinking milk due to intolerance) had an increased risk of colorectal cancer. This supports the ability of dairy products to reduce colorectal cancer risk and the causality of this relation. In the European EPIC study, the hypothesis that the genetically determined lactose tolerance was associated with elevated dairy product intake and increased prostate cancer risk was examined (89). The study included $630 \mathrm{men}$ with prostate cancer and 873 matched control participants. Dairy product consumption was assessed by diet questionnaires, and intake of milk and total dairy products varied significantly by lactase genotype, with an almost twofold higher intake in lactose-tolerant compared to lactose-intolerant subjects. However, the lactase variant was not found to be significantly associated with prostate cancer risk. This indicates that residual confounding may have biased the associations observed between milk and dairy intake and prostate cancer risk in the observational studies included in a previous meta-analysis (78).

Ji et al. (90) investigated Swedish subjects with selfreported lactose intolerance and found a lower risk of lung, breast, and ovarian cancers compared to lactose-tolerant subjects. Unfortunately, no information about milk intake, or other genetic, ethnic, lifestyle (diet, smoking and physical activity), and behavioural characteristics were reported. Also, self-reported lactose intolerance may not be comparable to genetically determined lactose intolerance. Due to potential bias in the design and the lack of control for known confounders, it is impossible to conclude about the relationship with dairy intake. Also, these findings are in contrast with the additional literature suggesting no or an inverse association between dairy intake and risk of breast cancer $(74,75)$, ovarian cancer $(83,91)$, and lung cancer $(84,85)$.

\section{Conclusion on cancer}

According to WCRF reports and the latest meta-analyses, consumption of milk and dairy products probably protects against colorectal cancer, bladder cancer, gastric cancer, and breast cancer. Dairy intake does not seem to be associated with risk of pancreatic cancer, ovarian cancer, or lung cancer, whereas the evidence for prostate cancer risk is inconsistent. In women, dairy offers significant and robust health benefits in reducing the risk of the common and serious colorectal cancer and, possibly, also the risk of breast cancer. In men, the benefit of the protective effect of milk and dairy on the common and serious colorectal cancer is judged to outweigh a potentially increased risk of prostate cancer.

\section{All-cause mortality}

In medical research, the term 'all-cause mortality' implies all causes of death. There are many individual studies reporting that a high consumption of milk and dairy products is associated with decreased mortality (92), unchanged mortality (93), or even increased mortality (94). However, based on meta-analyses of observational cohort studies, there is no evidence to support the view that milk and dairy product intake is associated with allcause mortality $(45,95)$. In a meta-analysis, O'Sullivan et al. (45) studied whether intake of milk and dairy products as food sources of saturated fat was related to all-cause mortality, cancer mortality, and cardiovascular mortality. Neither total dairy intake nor intake of any specific dairy products was found to be associated with all-cause mortality. In the most recent meta-analysis including 12 observational studies of milk intake and mortality, there were no consistent associations between milk intake and all-cause or cause-specific mortality (95).

\section{Conclusion on all-cause mortality}

The evidence from observational studies confirms that there is no association between consumption of milk and dairy products and all-cause mortality.

\section{Comparison of nutrient content and health aspects} of milk and plant-based drinks

In recent decades, the market for milk and dairy substitute drinks based on, for example, soy, rice, oats, or almonds has expanded, and calcium-fortified plant-based drinks have become part of the nutrition recommendations as alternatives to milk in several countries, such as the United States, Sweden, Australia, and Brazil. Among the plant-based milk substitutes, soy drink dominates the market in the Western world, but the emerging of other plant-based drinks has influenced the market for soy drink (96). 
The nutrient density of plant-based milk substitutes varies considerably between and within types, and their nutritional properties depend on the raw material used, the processing, the fortification with vitamins and minerals, and the addition of other ingredients such as sugar and oil. Soy drink is the only plant-based milk substitute that approximates the protein content of cow's milk, whereas the protein contents of the drinks based on oat, rice, and almonds are extremely low, and the recent review of Mäkinen et al. (96) emphasises the importance of consumer awareness of such low-protein contents. Moreover, there are now cases of severe nutritional deficiencies in children being reported as a result of inappropriate consumption of plant-based drinks $(97,98)$.

Despite the fact that most of the plant-based drinks are low in saturated fat and cholesterol, some of these products have higher energy contents than whole milk due to a high content of oil and added sugar. Some plant-based drinks have a sugar content equal to that of sugarsweetened beverages, which have been linked to obesity, reduced insulin sensitivity (99), increased liver, muscle, and visceral fat content as well as increased blood pressure, and increased concentrations of triglyceride and cholesterol in the blood $(100,101)$. Analyses of several commercially available plant-based drinks carried out at the Technical University of Denmark showed a generally higher energy content and lower contents of iodine, potassium, phosphorus, and selenium in the plant-based drinks compared to semi-skimmed milk (102). Also, rice drinks are known to have a high content of inorganic arsenic, and soy drinks are known to contain isoflavones with oestrogen-like effects. Consequently, The Danish Veterinary and Food Administration concluded that the plant-based drinks cannot be recommended as full worthy alternatives to cow's milk (102), which is consistent with the conclusions drawn by the Swedish National Food Agency (103).

The importance of studying whole foods instead of single nutrients is becoming clear as potential nutrientnutrient interactions may affect the metabolic response to the whole food compared to its isolated nutrients. As the plant-based drinks have undergone processing and fortification, any health effects of natural soy, rice, oats, and almonds cannot be directly transferred to the drinks, but need to be studied directly. Only a few studies have compared the effects of cow's milk with plant-based drinks as whole foods on disease risk markers (104-108). However, none of these have included commercially available drinks or disease endpoints. Therefore, the evidence is currently insufficient to conclude that plantbased drinks possess health benefits above those of milk and dairy products. Until more research has been conducted and a scientifically sound conclusion can be drawn, health authorities should be cautious about recommending plant-based drinks as acceptable substitutes to cow's milk for the general population.

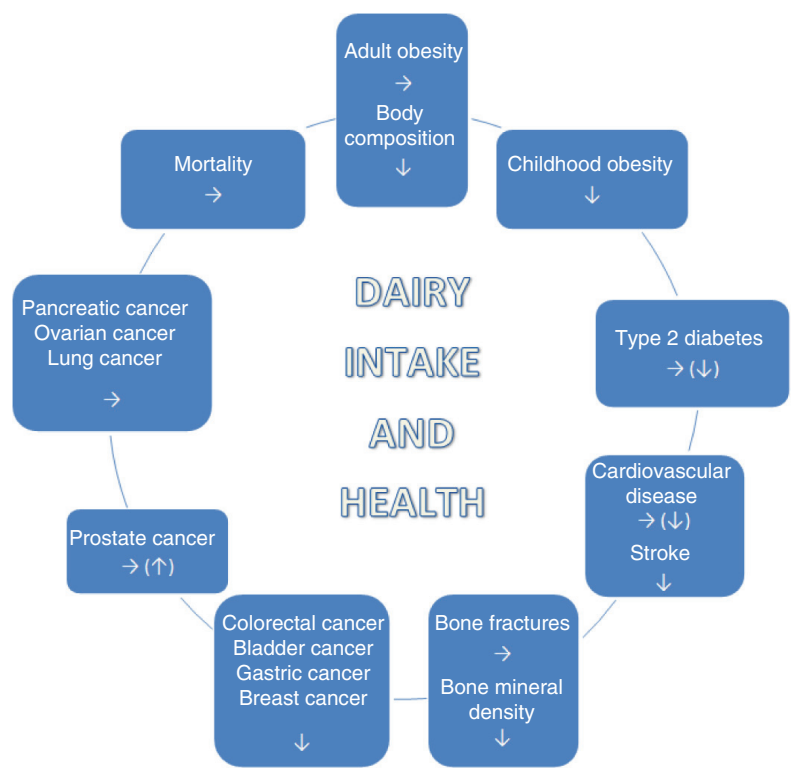

Fig. 1. Overall effect/association between dairy product intake and health outcomes. $\downarrow$ favourable effect/association; $\uparrow$ adverse effect/association; $\rightarrow$ no effect/association.

\section{Conclusion on nutrient content and health aspects of milk and plant-based drinks}

Cow's milk and plant-based drinks are completely different products, both regarding nutrient content and presumably also health effects. Although there are concerns about children consuming the low-protein drinks, further evidence-based assessment of the nutritional and health value of the plant-based drinks must await more studies in humans.

\section{Answers to the key questions}

Key question 1: For the general consumer, will a diet with milk and dairy products overall provide better or worse health, and increase or decrease risk of major diseases and all-cause mortality than a diet with no or low content of milk and dairy products?

Consumption of dairy products is associated with an overall reduced risk of cardiometabolic diseases and some cancers, whereas only very few adverse effects have been reported (Fig. 1). Dairy products may therefore have the potential to reduce the burden of the most prevalent chronic diseases in the population and to substantially reduce the health care costs for society (109). Consumption of dairy products is part of the dietary recommendations in several nations, for example, Sweden, Denmark, and United States. A general recommendation to reduce the intake of dairy products in individuals who actually tolerate them may be counterproductive for health and could therefore increase health care expenses. However, more emphasis should be on the foods which dairy replaces in the diet. In addition, as most of the conducted metaanalyses are on observational data, residual confounding 
cannot be ruled out, and it is also possible that milk and dairy intake in these studies could be just a marker of diets of higher nutritional quality.

Key question 2: Is it justified to recommend the general lactose-tolerant population to avoid the consumption of milk and dairy products?

In the Nordic countries, as few as $2 \%$ of the population has primary lactase deficiency and can be classified as lactose-intolerant individuals (110). Yet, most lactoseintolerant adults can tolerate one glass of milk or a scoop of ice cream. Cheeses have negligible lactose contents, and the lactose in yoghurt is digested more efficiently than other dairy sources due to the bacterial lactase present in yoghurt which facilitates lactose digestion (111). Therefore, fermented dairy products, that is, yoghurt and most cheeses (cottage cheese, as well as soft and hard cheeses), can be tolerated by lactose-intolerant individuals without symptoms $(111,112)$.

The same applies to cow's milk protein allergy that typically occurs in $0.1-2.0 \%$ of children in the Nordic countries and Europe (113). Among children with verified cow's milk-specific IgE who were re-evaluated 1 year after diagnosis, $69 \%$ tolerated cow's milk at re-evaluation (114). Thus, the condition is generally seen to resolve in children. To warn the general population against dairy consumption based on rare milk allergies would be equivalent to warn against foods, such as peanuts or seafood due to the fact that a small subset of the population is allergic to these foods.

Key question 3: Is there scientific evidence to substantiate that replacing milk and dairy products with plant-based drinks will improve health?

Cow's milk and plant-based drinks are not nutritionally comparable foods. As only a few studies have investigated the health effects of replacing cow's milk with plant-based drinks and none have focused on commercially available drinks or on disease endpoints, the effect of this replacement can only be speculated on. There have, however, been individual cases reporting illness in children consuming low-protein plant-based drinks, but an evidencebased final assessment of the health value of plant-based drinks compared to cow's milk must await more studies in humans.

Overall conclusions regarding intake of milk and dairy products and health

Our review of the totality of available scientific evidence supports that intake of milk and dairy products contributes to meeting nutrient recommendations and may protect against the most prevalent, chronic non-communicable diseases, whereas very few adverse effects have been reported.

\section{Conflicts of interest and funding}

Tanja Kongerslev Thorning has no conflicts of interest to declare. Anne Raben is recipient of research funding from the Dairy Research Institute, Rosemont, IL, USA and the Danish Agriculture \& Food Council.Tine Tholstrup is recipient of research grants from the Danish Dairy Research Foundation and the Dairy Research Institute, Rosemont, IL. The sponsors had no role in design and conduct of the studies, data collection and analysis, interpretation of the data, decision to publish, or preparation of the manuscripts. Sabita S. SoedamahMuthu received funding from the Global Dairy Platform, Dairy Research Institute and Dairy Australia for metaanalyses on cheese and blood lipids and on dairy and mortality. The sponsors had no role in design and conduct of the meta-analyses, data collection and analysis, interpretation of the data, decision to publish, or preparation of the manuscripts. Ian Givens is recipient of research grants from UK Biotechnology and Biological Sciences Research Council (BBSRC), UK Medical Research Council (MRC), Arla Foods UK, AAK-UK (both in kind), The Barham Benevolent Foundation, Volac UK, DSM Switzerland and Global Dairy Platform. He is a consultant for The Bio-competence Centre of Healthy Dairy Products, Tartu, Estonia, and in the recent past for The Dairy Council (London). Arne Astrup is recipient of research grants from Arla Foods, DK; Danish Dairy Research Foundation; Global Dairy Platform; Danish Agriculture \& Food Council; GEIE European Milk Forum, France. He is member of advisory boards for Dutch Beer Knowledge Institute, NL; IKEA, SV; Lucozade Ribena Suntory Ltd, UK; McCain Foods Limited, USA; McDonald's, USA; Weight Watchers, USA. He is a consultant for Nestlé Research Center, Switzerland; Nongfu Spring Water, China. Astrup receives honoraria as Associate Editor of American Journal of Clinical Nutrition, and for membership of the Editorial Boards of Annals of Nutrition and Metabolism and Annual Review of Nutrition. He is recipient of travel expenses and/ or modest honoraria $(<\$ 2,000)$ for lectures given at meetings supported by corporate sponsors. He received financial support from dairy organisations for attendance at the Eurofed Lipids Congress (2014) in France and the meeting of The Federation of European Nutrition Societies (2015) in Germany.

\section{References}

1. Park YW, Zhu S, Palaniappan L, Heshka S, Carnethon MR, Heymsfield SB. The metabolic syndrome: prevalence and associated risk factor findings in the US population from the Third National Health and Nutrition Examination Survey, 1988-1994. Arch Intern Med 2003; 163(4): 427-36.

2. Laaksonen MA, Knekt P, Rissanen H, Harkanen T, Virtala E, Marniemi $\mathrm{J}$, et al. The relative importance of modifiable 
potential risk factors of type 2 diabetes: a meta-analysis of two cohorts. Eur J Epidemiol 2010; 25(2): 115-24.

3. Dietz WH, Gortmaker SL. Preventing obesity in children and adolescents. Annu Rev Public Health 2001; 22: 337-53.

4. Dror DK. Dairy consumption and pre-school, school-age and adolescent obesity in developed countries: a systematic review and meta-analysis. Obes Rev 2014; 15(6): 516-27.

5. Lu L, Xun P, Wan Y, He K, Cai W. Long-term association between dairy consumption and risk of childhood obesity: a systematic review and meta-analysis of prospective cohort studies. Eur J Clin Nutr 2016; 70(4): 414-23.

6. Gilbert JA, Bendsen NT, Tremblay A, Astrup A. Effect of proteins from different sources on body composition. Nutr Metab Cardiovasc Dis 2011; 21(Suppl 2): B16-31.

7. Bendtsen LQ, Lorenzen JK, Bendsen NT, Rasmussen C, Astrup A. Effect of dairy proteins on appetite, energy expenditure, body weight, and composition: a review of the evidence from controlled clinical trials. Adv Nutr 2013; 4(4): 418-38.

8. Astrup A, Raben A, Geiker N. The role of higher protein diets in weight control and obesity-related comorbidities. Int J Obes (Lond) 2015; 39(5): 721-6.

9. Abargouei AS, Janghorbani M, Salehi-Marzijarani M, Esmaillzadeh A. Effect of dairy consumption on weight and body composition in adults: a systematic review and metaanalysis of randomized controlled clinical trials. Int $\mathbf{J}$ Obes (Lond) 2012; 36(12): 1485-93.

10. Chen M, Pan A, Malik VS, Hu FB. Effects of dairy intake on body weight and fat: a meta-analysis of randomized controlled trials. Am J Clin Nutr 2012; 96(4): 735-47.

11. Booth AO, Huggins CE, Wattanapenpaiboon N, Nowson CA. Effect of increasing dietary calcium through supplements and dairy food on body weight and body composition: a meta-analysis of randomised controlled trials. Br J Nutr 2015; 114(7): 1013-25.

12. Maghsoudi Z, Ghiasvand R, Salehi-Abargouei A. Empirically derived dietary patterns and incident type 2 diabetes mellitus: a systematic review and meta-analysis on prospective observational studies. Public Health Nutr 2016; 19(2): 230-41.

13. Gao D, Ning N, Wang C, Wang Y, Li Q, Meng Z, et al. Dairy products consumption and risk of type 2 diabetes: systematic review and dose-response meta-analysis. PLoS One 2013; 8(9): e73965.

14. Aune D, Norat T, Romundstad P, Vatten LJ. Dairy products and the risk of type 2 diabetes: a systematic review and doseresponse meta-analysis of cohort studies. Am J Clin Nutr 2013; 98(4): 1066-83.

15. Tong X, Dong JY, Wu ZW, Li W, Qin LQ. Dairy consumption and risk of type 2 diabetes mellitus: a meta-analysis of cohort studies. Eur J Clin Nutr 2011; 65(9): 1027-31.

16. Bergholdt HK, Nordestgaard BG, Ellervik C. Milk intake is not associated with low risk of diabetes or overweight-obesity: a Mendelian randomization study in 97,811 Danish individuals. Am J Clin Nutr 2015; 102(2): 487-96.

17. Gijsbers L, Ding EL, Malik VS, de Goede J, Geleijnse JM, Soedamah-Muthu SS. Consumption of dairy foods and diabetes incidence: a dose-response meta-analysis of observational studies. Am J Clin Nutr 2016; 103(4): 1111-24.

18. Astrup A. A changing view on saturated fatty acids and dairy: from enemy to friend. Am J Clin Nutr 2014; 100(6): 1407-8.

19. Zheng H, Yde CC, Clausen MR, Kristensen M, Lorenzen J, Astrup A, et al. Metabolomics investigation to shed light on cheese as a possible piece in the French paradox puzzle. J Agr Food Chem 2015; 63(10): 2830-9.

20. Frid AH, Nilsson M, Holst JJ, Bjorck IM. Effect of whey on blood glucose and insulin responses to composite breakfast and lunch meals in type 2 diabetic subjects. Am J Clin Nutr 2005; 82(1): 69-75.

21. Nilsson M, Stenberg M, Frid AH, Holst JJ, Bjorck IM. Glycemia and insulinemia in healthy subjects after lactoseequivalent meals of milk and other food proteins: the role of plasma amino acids and incretins. Am J Clin Nutr 2004; 80(5): 1246-53.

22. Rideout TC, Marinangeli CP, Martin H, Browne RW, Rempel CB. Consumption of low-fat dairy foods for 6 months improves insulin resistance without adversely affecting lipids or bodyweight in healthy adults: a randomized free-living crossover study. Nutr J 2013; 12: 56.

23. Soedamah-Muthu SS, Verberne LD, Ding EL, Engberink MF, Geleijnse JM. Dairy consumption and incidence of hypertension: a dose-response meta-analysis of prospective cohort studies. Hypertension 2012; 60(5): 1131-7.

24. Huth PJ, Park KM. Influence of dairy product and milk fat consumption on cardiovascular disease risk: a review of the evidence. Adv Nutr 2012; 3(3): 266-85.

25. Musunuru K, Orho-Melander M, Caulfield MP, Li S, Salameh WA, Reitz RE, et al. Ion mobility analysis of lipoprotein subfractions identifies three independent axes of cardiovascular risk. Arterioscler Thromb Vasc Biol 2009; 29(11): 1975-80.

26. St-Pierre AC, Cantin B, Dagenais GR, Mauriege P, Bernard PM, Despres JP, et al. Low-density lipoprotein subfractions and the long-term risk of ischemic heart disease in men: 13-year follow-up data from the Quebec Cardiovascular Study. Arterioscler Thromb Vasc Biol 2005; 25(3): 553-9.

27. Mora S, Buring JE, Ridker PM, Cui Y. Association of highdensity lipoprotein cholesterol with incident cardiovascular events in women, by low-density lipoprotein cholesterol and apolipoprotein B100 levels: a cohort study. Ann Intern Med 2011; 155(11): 742-50.

28. Krauss RM. Lipoprotein subfractions and cardiovascular disease risk. Curr Opin Lipidol 2010; 21(4): 305-11.

29. Berneis KK, Krauss RM. Metabolic origins and clinical significance of LDL heterogeneity. J Lipid Res 2002; 43(9): 1363-79.

30. Sjogren P, Rosell M, Skoglund-Andersson C, Zdravkovic S, Vessby B, de Faire U, et al. Milk-derived fatty acids are associated with a more favorable LDL particle size distribution in healthy men. J Nutr 2004; 134(7): 1729-35.

31. Lorenzen JK, Astrup A. Dairy calcium intake modifies responsiveness of fat metabolism and blood lipids to a highfat diet. Br J Nutr 2011; 105: 1-10.

32. Soerensen KV, Thorning TK, Astrup A, Kristensen M, Lorenzen JK. Effect of dairy calcium from cheese and milk on fecal fat excretion, blood lipids, and appetite in young men. Am J Clin Nutr 2014; 95(5): 984-91.

33. Hjerpsted J, Leedo E, Tholstrup T. Cheese intake in large amounts lowers LDL-cholesterol concentrations compared with butter intake of equal fat content. Am J Clin Nutr 2011; 94(6): 1479-84.

34. Thorning TK, Raziani F, Bendsen NT, Astrup A, Tholstrup T, Raben A. Diets with high-fat cheese, high-fat meat, or carbohydrate on cardiovascular risk markers in overweight postmenopausal women: a randomized crossover trial. Am J Clin Nutr 2015; 102(3): 573-81.

35. Raziani F, Tholstrup T, Kristensen MD, Svanegaard ML, Ritz C, Astrup A, et al. High intake of regular-fat cheese compared with reduced-fat cheese does not affect LDL cholesterol or risk markers of the metabolic syndrome: a randomized controlled trial. Am J Clin Nutr 2016; 104(4): 973-981.

36. de Goede J, Geleijnse JM, Ding EL, Soedamah-Muthu SS. Effect of cheese consumption on blood lipids: a systematic 
review and meta-analysis of randomized controlled trials. Nutr Rev 2015; 73(5): 259-75.

37. Tholstrup T, Hoy CE, Andersen LN, Christensen RD, Sandstrom B. Does fat in milk, butter and cheese affect blood lipids and cholesterol differently? J Am Coll Nutr 2004; 23(2): 169-76.

38. Soedamah-Muthu SS, Ding EL, Al-Delaimy WK, Hu FB, Engberink MF, Willett WC, et al. Milk and dairy consumption and incidence of cardiovascular diseases and all-cause mortality: dose-response meta-analysis of prospective cohort studies. Am J Clin Nutr 2011; 93(1): 158-71.

39. Hu D, Huang J, Wang Y, Zhang D, Qu Y. Dairy foods and risk of stroke: a meta-analysis of prospective cohort studies. Nutr Metab Cardiovasc Dis 2014; 24(5): 460-9.

40. de Goede J, Soedamah-Muthu SS, Pan A, Gijsbers L, Geleijnse JM. Dairy consumption and risk of stroke: a systematic review and updated doseresponse meta-analysis of prospective cohort studies. J Am Heart Assoc 2016; 5(5): e002787, doi: http://dx.doi.org/10.1161/JAHA.115.002787

41. Rice BH. Dairy and cardiovascular disease: a review of recent observational research. Curr Nutr Rep 2014; 3: 130-8.

42. Qin LQ, Xu JY, Han SF, Zhang ZL, Zhao YY, Szeto IM. Dairy consumption and risk of cardiovascular disease: an updated meta-analysis of prospective cohort studies. Asia Pac J Clin Nutr 2015; 24(1): 90-100.

43. Alexander DD, Bylsma LC, Vargas AJ, Cohen SS, Doucette A, Mohamed M, et al. Dairy consumption and CVD: a systematic review and meta-analysis. Br J Nutr 2016; 115(4): 737-50.

44. Chowdhury R, Warnakula S, Kunutsor S, Crowe F, Ward HA, Johnson L, et al. Association of dietary, circulating, and supplement fatty acids with coronary risk: a systematic review and meta-analysis. Ann Intern Med 2014; 160(6): 398-406.

45. O’Sullivan TA, Hafekost K, Mitrou F, Lawrence D. Food sources of saturated fat and the association with mortality: a meta-analysis. Am J Public Health 2013; 103(9): e31-42.

46. Mursu J, Steffen LM, Meyer KA, Duprez D, Jacobs DR Jr. Diet quality indexes and mortality in postmenopausal women: the Iowa Women's Health Study. Am J Clin Nutr 2013; 98(2): $444-53$.

47. Nordic Council of Ministers (2014). Nordic nutrition recommendations 2012-integrating nutrition and physical activity, 5th edition. Copenhagen, DK: Nordic Council of Ministers.

48. Rizzoli R. Dairy products, yogurts, and bone health. Am J Clin Nutr 2014; 99(5 Suppl): 1256S-62S.

49. Kalkwarf HJ, Khoury JC, Lanphear BP. Milk intake during childhood and adolescence, adult bone density, and osteoporotic fractures in US women. Am J Clin Nutr 2003; 77(1): 257-65.

50. Power ML, Heaney RP, Kalkwarf HJ, Pitkin RM, Repke JT, Tsang RC, et al. The role of calcium in health and disease. Am J Obstet Gynecol 1999; 181(6): 1560-9.

51. Abrams SA, Chen Z, Hawthorne KM. Magnesium metabolism in 4-year-old to 8-year-old children. J Bone Miner Res 2014; 29(1): 118-22.

52. Huncharek M, Muscat J, Kupelnick B. Impact of dairy products and dietary calcium on bone-mineral content in children: results of a meta-analysis. Bone 2008; 43(2): 312-21.

53. Bonjour JP, Kraenzlin M, Levasseur R, Warren M, Whiting S. Dairy in adulthood: from foods to nutrient interactions on bone and skeletal muscle health. J Am Coll Nutr 2013; 32(4): 251-63.

54. Bischoff-Ferrari HA, Dawson-Hughes B, Baron JA, Kanis JA, Orav EJ, Staehelin HB, et al. Milk intake and risk of hip fracture in men and women: a meta-analysis of prospective cohort studies. J Bone Miner Res 2011; 26(4): 833-9.
55. Kanis JA, Johansson H, Oden A, De Laet C, Johnell O, Eisman JA, et al. A meta-analysis of milk intake and fracture risk: low utility for case finding. Osteoporos Int 2005; 16(7): 799-804.

56. Weaver CM. Calcium supplementation: is protecting against osteoporosis counter to protecting against cardiovascular disease? Curr Osteoporos Rep 2014; 12(2): 211-18.

57. Bolland MJ, Grey A, Reid IR. Calcium supplements and cardiovascular risk: 5 years on. Ther Adv Drug Saf 2013; 4(5): 199-210.

58. Astrup A. Yogurt and dairy product consumption to prevent cardiometabolic diseases: epidemiologic and experimental studies. Am J Clin Nutr 2014; 99(5 Suppl): 1235S-42S.

59. Latino-Martel P, Cottet V, Druesne-Pecollo N, Pierre FH, Touillaud M, Touvier M, et al. Alcoholic beverages, obesity, physical activity and other nutritional factors, and cancer risk: a review of the evidence. Crit Rev Oncol Hematol 2016; 99: 308-23.

60. World Cancer Research Fund/American Institute for Cancer Research (2011). Food, nutrition, physical activity, and the prevention of colorectal cancer. London, UK: WCRF International.

61. Lampe JW. Dairy products and cancer. J Am Coll Nutr 2011; 30(5 Suppl 1): 464S-70S.

62. Aune D, Lau R, Chan DS, Vieira R, Greenwood DC, Kampman E, et al. Dairy products and colorectal cancer risk: a systematic review and meta-analysis of cohort studies. Ann Oncol 2012; 23(1): 37-45.

63. Huncharek M, Muscat J, Kupelnick B. Colorectal cancer risk and dietary intake of calcium, vitamin $\mathrm{D}$, and dairy products: a meta-analysis of 26,335 cases from 60 observational studies. Nutr Cancer 2009; 61(1): 47-69.

64. Ralston RA, Truby H, Palermo CE, Walker KZ. Colorectal cancer and nonfermented milk, solid cheese, and fermented milk consumption: a systematic review and meta-analysis of prospective studies. Crit Rev Food Sci Nutr 2014; 54(9): 1167-79.

65. Keum N, Aune D, Greenwood DC, Ju W, Giovannucci EL. Calcium intake and colorectal cancer risk: dose-response meta-analysis of prospective observational studies. Int $\mathbf{J}$ Cancer 2014; 135(8): 1940-8.

66. Newmark HL, Wargovich MJ, Bruce WR. Colon cancer and dietary fat, phosphate, and calcium: a hypothesis. J Natl Cancer Inst 1984; 72(6): 1323-5.

67. Lamprecht SA, Lipkin M. Cellular mechanisms of calcium and vitamin $\mathrm{D}$ in the inhibition of colorectal carcinogenesis. Ann N Y Acad Sci 2001; 952: 73-87.

68. Holt PR, Atillasoy EO, Gilman J, Guss J, Moss SF, Newmark $\mathrm{H}$, et al. Modulation of abnormal colonic epithelial cell proliferation and differentiation by low-fat dairy foods: a randomized controlled trial. JAMA 1998; 280(12): 1074-9.

69. Holt PR, Wolper C, Moss SF, Yang K, Lipkin M. Comparison of calcium supplementation or low-fat dairy foods on epithelial cell proliferation and differentiation. Nutr Cancer 2001; 41(1-2): $150-5$

70. Karagas MR, Tosteson TD, Greenberg ER, Rothstein RI, Roebuck BD, Herrin M, et al. Effects of milk and milk products on rectal mucosal cell proliferation in humans. Cancer Epidemiol Biomarkers Prev 1998; 7(9): 757-66.

71. Rozen P, Lubin F, Papo N, Knaani J, Farbstein H, Farbstein $\mathrm{M}$, et al. Calcium supplements interact significantly with longterm diet while suppressing rectal epithelial proliferation of adenoma patients. Cancer 2001; 91(4): 833-40.

72. Ahearn TU, McCullough ML, Flanders WD, Long Q, Sidelnikov E, Fedirko V, et al. A randomized clinical trial of the effects of supplemental calcium and vitamin D3 on markers of their metabolism in normal mucosa of colorectal adenoma patients. Cancer Res 2011; 71(2): 413-23. 
73. World Cancer Research Fund/American Institute for Cancer Research (2010). Food, nutrition, physical activity, and the prevention of breast cancer. London, UK: WCRF International.

74. Dong JY, Zhang L, He K, Qin LQ. Dairy consumption and risk of breast cancer: a meta-analysis of prospective cohort studies. Breast Cancer Res Treat 2011; 127(1): 23-31.

75. Zang J, Shen M, Du S, Chen T, Zou S. The association between dairy intake and breast cancer in western and Asian populations: a systematic review and meta-analysis. $\mathbf{J}$ Breast Cancer 2015; 18(4): 313-22.

76. Cauley JA, Chlebowski RT, Wactawski-Wende J, Robbins JA, Rodabough RJ, Chen Z, et al. Calcium plus vitamin D supplementation and health outcomes five years after active intervention ended: the women's health initiative. J Womens Health (Larchmt) 2013; 22(11): 915-29.

77. World Cancer Research Fund International/American Institute for Cancer Research (2014). Diet, nutrition, physical activity, and prostate cancer. London, UK: WCRF International.

78. Aune D, Navarro Rosenblatt DA, Chan DS, Vieira AR, Vieira R, Greenwood DC, et al. Dairy products, calcium, and prostate cancer risk: a systematic review and meta-analysis of cohort studies. Am J Clin Nutr 2015; 101(1): 87-117.

79. Roddam AW, Allen NE, Appleby P, Key TJ, Ferrucci L, Carter $\mathrm{HB}$, et al. Insulin-like growth factors, their binding proteins, and prostate cancer risk: analysis of individual patient data from 12 prospective studies. Ann Intern Med 2008; 149(7): 461-71, W83-8.

80. World Cancer Research Fund International/American Institute for Cancer Research (2015). Diet, nutrition, physical activity and bladder cancer. London, UK: WCRF International.

81. Mao QQ, Dai Y, Lin YW, Qin J, Xie LP, Zheng XY. Milk consumption and bladder cancer risk: a meta-analysis of published epidemiological studies. Nutr Cancer 2011; 63(8): 1263-71.

82. Li F, An SL, Zhou Y, Liang ZK, Jiao ZJ, Jing YM, et al. Milk and dairy consumption and risk of bladder cancer: a meta-analysis. Urology 2011; 78(6): 1298-305.

83. Hou R, Wu QJ, Gong TT, Jiang L. Dietary fat and fatty acid intake and epithelial ovarian cancer risk: evidence from epidemiological studies. Oncotarget 2015; 6(40): 43099-119.

84. Yu Y, Li H, Xu K, Li X, Hu C, Wei H, et al. Dairy consumption and lung cancer risk: a meta-analysis of prospective cohort studies. Onco Targets Ther 2015; 9: 111-16.

85. Yang Y, Wang X, Yao Q, Qin L, Xu C. Dairy product, calcium intake and lung cancer risk: a systematic review with metaanalysis. Sci Rep 2016; 6: 20624.

86. Genkinger JM, Wang M, Li R, Albanes D, Anderson KE, Bernstein L, et al. Dairy products and pancreatic cancer risk: a pooled analysis of 14 cohort studies. Ann Oncol 2014; 25(6): 1106-115.

87. Guo Y, Shan Z, Ren H, Chen W. Dairy consumption and gastric cancer risk: a meta-analysis of epidemiological studies. Nutr Cancer 2015; 67(4): 555-68.

88. Bácsi K, Hitre E, Kosa JP, Horvath H, Lazary A, Lakatos PL, et al. Effects of the lactase $13910 \mathrm{C} / \mathrm{T}$ and calcium-sensor receptor A986S G/T gene polymorphisms on the incidence and recurrence of colorectal cancer in Hungarian population. BMC Cancer 2008; 8: 317.

89. Travis RC, Appleby PN, Siddiq A, Allen NE, Kaaks R, Canzian F, et al. Genetic variation in the lactase gene, dairy product intake and risk for prostate cancer in the European prospective investigation into cancer and nutrition. Int $\mathrm{J}$ Cancer 2013; 132(8): 1901-10.

90. Ji J, Sundquist J, Sundquist K. Lactose intolerance and risk of lung, breast and ovarian cancers: aetiological clues from a population-based study in Sweden. Br J Cancer 2015; 112(1): $149-52$.

91. Merritt MA, Poole EM, Hankinson SE, Willett WC, Tworoger SS. Dairy food and nutrient intake in different life periods in relation to risk of ovarian cancer. Cancer Causes Control 2014; 25(7): 795-808.

92. Wang C, Yatsuya H, Tamakoshi K, Iso H, Tamakoshi A. Milk drinking and mortality: findings from the Japan collaborative cohort study. J Epidemiol 2015; 25(1): 66-73.

93. Paganini-Hill A, Kawas CH, Corrada MM. Non-alcoholic beverage and caffeine consumption and mortality: the Leisure World Cohort Study. Prev Med 2007; 44(4): 305-10.

94. Michaelsson K, Wolk A, Langenskiold S, Basu S, Warensjo Lemming E, Melhus H, et al. Milk intake and risk of mortality and fractures in women and men: cohort studies. BMJ 2014; 349: g6015.

95. Larsson SC, Crippa A, Orsini N, Wolk A, Michaelsson K. Milk consumption and mortality from all causes, cardiovascular disease, and cancer: a systematic review and metaanalysis. Nutrients 2015; 7(9): 7749-63.

96. Mäkinen OE, Wanhalinna V, Zannini E, Arendt EK. Foods for special dietary needs: non-dairy plant based milk substitutes and fermented dairy type products. Crit Rev Food Sci Nutr 2016; 56(3): 339-49.

97. Ellis D, Lieb J. Hyperoxaluria and genitourinary disorders in children ingesting almond milk products. J Pediatr 2015; 167(5): 1155-8.

98. Le Louer B, Lemale J, Garcette K, Orzechowski C, Chalvon A, Girardet JP, et al. Severe nutritional deficiencies in young infants with inappropriate plant milk consumption. Arch Pediatr 2014; 21(5): 483-8.

99. Jakobsen MU, Dethlefsen C, Joensen AM, Stegger J, Tjonneland A, Schmidt EB, et al. Intake of carbohydrates compared with intake of saturated fatty acids and risk of myocardial infarction: importance of the glycemic index. Am J Clin Nutr 2010; 91(6): 1764-8.

100. Maersk M, Belza A, Stodkilde-Jorgensen H, Ringgaard S, Chabanova E, Thomsen H, et al. Sucrose-sweetened beverages increase fat storage in the liver, muscle, and visceral fat depot: a 6-mo randomized intervention study. Am J Clin Nutr 2012; 95(2): 283-9.

101. Raben A, Moller BK, Flint A, Vasilaris TH, Christina Moller A, Juul Holst J, et al. Increased postprandial glycaemia, insulinemia, and lipidemia after 10 weeks' sucrose-rich diet compared to an artificially sweetened diet: a randomised controlled trial. Food Nutr Res 2011; 55. doi: http://dx.doi.org/10. 3402/fnr.v55i0.5961

102. Fødevarestyrelsen (2015). Slutrapport: Næringsstofindhold i ris-, havre-, mandel- og sojadrikke. Glostrup, Denmark: Ministry of Environment and Food of Denmark.

103. Konde ÅB, Bjerselius R, Haglund L, Jansson A, Pearson M, Färnstrand JS, et al. Råd om bra matvanor - risk- och nyttohanteringsrapport. Uppsala, Sweden: Livsmedelsverket; 2015, Rapport 5.

104. Gardner CD, Messina M, Kiazand A, Morris JL, Franke AA. Effect of two types of soy milk and dairy milk on plasma lipids in hypercholesterolemic adults: a randomized trial. J Am Coll Nutr 2007; 26(6): 669-77.

105. Beavers KM, Serra MC, Beavers DP, Cooke MB, Willoughby DS. Soymilk supplementation does not alter plasma markers of inflammation and oxidative stress in postmenopausal women. Nutr Res 2009; 29(9): 616-22.

106. Beavers KM, Serra MC, Beavers DP, Hudson GM, Willoughby DS. The lipid-lowering effects of 4 weeks of daily soymilk or dairy milk ingestion in a postmenopausal female population. J Med Food 2010; 13(3): 650-6. 
107. Onning G, Akesson B, Oste R, Lundquist I. Effects of consumption of oat milk, soya milk, or cow's milk on plasma lipids and antioxidative capacity in healthy subjects. Ann Nutr Metab 1998; 42(4): 211-20.

108. Lindstrom C, Voinot A, Forslund A, Holst O, Rascon A, Oste $\mathrm{R}$, et al. An oat bran-based beverage reduce postprandial glycaemia equivalent to yoghurt in healthy overweight subjects. Int J Food Sci Nutr 2015; 66(6): 700-5.

109. Doidge JC, Segal L, Gospodarevskaya E. Attributable risk analysis reveals potential healthcare savings from increased consumption of dairy products. J Nutr 2012; 142(9): 1772-80.

110. Heyman MB, Committee on Nutrition. Lactose intolerance in infants, children, and adolescents. Pediatrics 2006; 118(3): 1279-86.

111. Savaiano DA. Lactose digestion from yogurt: mechanism and relevance. Am J Clin Nutr 2014; 99(5 Suppl): 1251S-5S.

112. Sieber R, Stransky M, de Vrese M. Lactose intolerance and consumption of milk and milk products. Z Ernahrungswiss 1997; 36(4): 375-93.
113. Schoemaker AA, Sprikkelman AB, Grimshaw KE, Roberts G, Grabenhenrich L, Rosenfeld L, et al. Incidence and natural history of challenge-proven cow's milk allergy in European children - EuroPrevall birth cohort. Allergy 2015; 70(8): 963-72.

114. Host A, Halken S, Jacobsen HP, Christensen AE, Herskind AM, Plesner K. Clinical course of cow's milk protein allergy/ intolerance and atopic diseases in childhood. Pediatr Allergy Immunol 2002; 13(Suppl 15): 23-8.

\section{*Arne Astrup}

Department of Nutrition, Exercise and Sports Faculty of Science, University of Copenhagen Noerre Alle 5I, DK-2200 Copenhagen N

Denmark

Email: ast@nexs.ku.dk 